\title{
АСПЕКТИ НА СИГУРНОСТТА НА ИНФОРМАЦИЯТА В СПЕЦИАЛИЗИРАНИ СИСТЕМИ В ЗДРАВЕОПАЗВАНЕТО
}

\author{
Ю. Каракънева
}

\section{SOME ASPECTS OF INFORMATION SECURITY CONCERNING SPECIALIZED HEALTHCARE SYSTEMS}

\section{J. Karakaneva}

Рез юме. В доклада се разглеждат въпроси, свързани с информационната сигурност в специализираните системи за здравеопазването. Очертани са предизвикателствата пред защитата на информационните ресурси и основните направления за решаване на поставените задачи. Дефинирани са категории информация, подлежащи на защита, и са предложени административни, физически и технологични мерки за редуциране на риска и постигане на сигурност. Дискутирани са нерешените проблеми в условията на променящата се среда за сигурност.

$S$ u $\mathbf{m} \boldsymbol{m}$ ary. The report examines the issues related to the information security of specialized systems in healthcare. The author outlines the challenges facing the protection of information resources and the main directions for solving the tasks. The categories of information subject to protection are defined. The administrative, physical and technological measures to reduce the risk and achieve security are proposed. The unresolved problems and security gaps in the changing security environment are discussed.

Key words: information security, cybersecurity, information systems in healthcare, personal data protection.

\section{УвоА}

Въвеждането в експлоатация на съвременни уеббазирани информационни системи в различни области на държавното и местното управление е процес, който бележи развитие в последните години, особено във връзка със създаването на интегрираната система за електронно правителство и електронно управление.

Една от областите, в които интензивно се прилагат информационните и комуникационните технологии е здравеопазването и медицинското обслужване. В редица европейски държави, както и в САЩ [1] информационните системи за управление на здравната информация са вече факт и в продължение на години се усъвършенства нормативната база за регламентиране на достъпа и използването на тази информация. Приет е международен стандарт ISO 21549 [2], третиращ въпросите на управлението на здравната информация в електронните медицински досиета.

В Република България Националната здравна информационна система е в процес на разработване, а на Интернет страницата на Националната здравноосигурителна каса функционира приложение за електронно поддържане на здравната информация $[3,4]$, но не са създадени специални нормативни актове, регламентиращи изискванията към целия жизнен цикъл на информацията за здравето на пациентите [5]. В българското законодателство тези въпроси се третират частично в Закона за защита на личните данни [6].

Информацията за здравето ${ }^{1}$, която се създава, обработва, пренася и съхранява в информационни системи в електронен вид е категория „чувствителна“ информация, която подлежи на защита, защото съдържа лични данни за пациентите и в този смисъл се отнася до неприкосновеността на личното пространство на всеки член на обществото. В Европейската харта за права̀та на пациентите (2012) [4] се дефинира правото на тайна и конфиденциалност: „Всяко лище има право на конфиденциалност по отношение на личната информация, включително информацията за здравословното състояние и за възможните диагностични или терапевтични процедури, както и на защчита на личната тайна при извършване на диагностични прегледи, посещения на специалисти и общя медицинско лечение и хирургически намеси".
В националното законодателство на европейските страни се разглеждат въпросите за сигурността на информацията, която съдържат електронните медицински досиета $(\text { ЕМД })^{2}$. Основните аспекти, които са обект на внимание са правилата за достъп и защитата от неопълномощен достьп, използване, разкриване, модификация и унищожаване на информацията. Сигурността на информацията се постига чрез гарантиране на тайната, целостта и наличността в целия ѝ жизнен цикъл.

В контекста на здравния сектор това означава:

- електронната здравна информация (ЕЗИ) не може да бъде достъпна или да се разкрива от неупълномощени лица или процеси;

- ЕЗИ не може да бъде модифицирана или унищожавана по нерегламентиран начин;

- ЕЗИ трябва да бъде на разположение при заявка от страна на опълномощен потребител.

Категорията „здравна информация““ се нуждае от специална защита поради характера на тази информация - лични данни за здравния статус на всеки гражданин и възможността да се използва разкритата информация за злоумишлени цели, за увреждане на репутацията или нанасяне на други вреди на засегнатите лица.

В документа Health Insurance Portability and Accountability Act (HIPAA) [8] на американския конгрес се третират основните характеристики на здравната информация: поверителност, неприкосновеност и сигурност.

Поверителността е свързана с практиката да се позволи само на опълномощени лица да имат достъп до информация със задължението, че те ще я оповестяват само на други упълномощени лица, в съответствие със законовите норми.

Неприкосновеност е правото на индивида да контролира своята защитена здравна информация.

Сигурността е свързана с административни, технически или физически мерки, въведени, за да се осигури защитата на здравната информация.

Силно чувствителните медицински данни включват определени категории като състояния, тестове, изследвания, както и целите досиета на уязвими, специфични или непълнолетни пациенти. Прилагането на защитни мерки за такива категории е предизвикателство, защото е необходима спе-

\footnotetext{
В доклада се използват в същия смисъл термините „здравна информация“ и „медицинска информация“.

2 В същия смисъл се използва термина „електронно здравно досие“.
} 
цифична функционалност на информационната система. По-долу се разглеждат някои от тези категории информация.

В някои държави [9] законът дава специална защита на определени диагнози или състояния. Електронните системи трябва да могат да идентифицират и управляват тези типове данни по подходящ начин. Например, здравните досиета на психично болни пациенти обикновено са с по-висока степен на поверителност, тъй като те съдържат специфична информация на пациента. Много от лицата, получаващи услуги по въпросите на психичното здраве, са уязвими и личното им пространство трябва да бъде защитено и да се гарантира, че им се предоставят същите условия на живот, както на другите индивиди в общността. По този начин те не могат да станат жертва на кражба на самоличност или измама.

Досиетата на пациенти, съдържащи информация за злоупотреба с химични вещества и съответните зависимости, както и на болните от ХИВ/СПИН се нуждаят от специално внимание. Записите в тази категория не се разкриват в отговор на призовка, освен ако са придружени от подписано съгласие на пациента или в съответствие с валиден съдебен ред. Здравните заведения трябва да имат възможност да управляват тези досиета, тъй като лечението на пациентите може да обхване няколко медицински специалности и да се отразява в различни видове електронни документи.

Категориите информация, които се отнасят до процедури, операции и тестове, свързани със семейното планиране, генетичните тестове и пластичната хирургия представляват друга високо-рискова категория, тъй като тези процедури са обусловени от лични и религиозни вярвания и могат да повлияят на застрахователни обстоятелства.

Има сериозни проблеми, свързани с неприкосновеността на личния живот и генетичните изследвания. Индивидите са изправени пред страх от дискриминация, загуба на здравна застраховка или застраховка живот на основата на информация за установени генетични аномалии. Отказът да се използват ефективни генетични тестове по тези причини пречи на хората да получат своевременна медицинска помощ и активно да управляват своето здраве.

Например документът Genetic Information Nondiscrimination Act на американския конгрес (2008) забранява дискриминацията въз основа на генетична информация по отношение на здравното осигуряване и заетостта. Държавни и федерални закони съдържат текстове, насочени срещу незаконното използване на генетични данни и третират въпроса дали работодателите и застрахователните дружества трябва да имат достьп до генетичната информация.

Други категории информация, подлежащи на защита ca: досиетата на недееспособни или некомпетентни лица, лишени от свобода или задържани лица, непълнолетни и страни, участващи в процедури за осиновяване, както и починали. С особена защита се ползва информацията за доброволци или пациенти, участници в клинични изпитания или изследователски процедури.

\section{Предпоставки за решаване на проблема}

Основните направления, в които се търсят решения на формулираните проблеми са:

- работа на здравните организации по идентифициране на категориите информация, нуждаещи се от защита;

- оценяване на риска по отношение сигурността на чувствителната информация;

р разработване на стратегия, политики и процедури за сигурност;

\section{средства; \\ - избор на подходящи технологични и технически \\ - работа на регулаторните органи за създаване на} необходимите нормативни документи.

В медицинската практика следва да се прилагат изискванията за сигурност на информацията в електронните системи в интерес на пациентите. Извършва се оценяване на риска от неоторизиран достъп до чувствителните данни и необходимостта от прилагане на специфични методи и средства за защита, чиито аспекти ще бъдат разгледани подолу.

Един такъв проблем, например, е установяването на автентичността на самоличността на пациентите и достоверното свързване на пациентите с техните досиета. Необходимо е прилагането на надеждни методи за автентикация, тъй като този аспект е от съществено значение както за предоставяне на качествени грижи, така и за подобряване на безопасността на пациентите, особено, когато информацията се споделя от различни здравни заведения.

Има голямо разнообразие от софтуерни системи, които се използват от личните лекари и медицинските организации и в общия случай не съществува съвместимост на ниво данни и възможност за обмен на данни. Поради тази причина е трудно извършването на уникална идентификация на пациентите в рамките на няколко здравни заведения. Необходимо е да се развие система за идентифициране на пациентите между здравните заведения и да се установи оперативна съвместимост между функциониращите информационни системи. Понастоящем в тази сфера не съществуват стандарти за съвместимост на данните.

Защитата на информацията за пациента е от решаващо значение за предотвратяване на кражба на самоличност, кражба на медицинска самоличност, измами и злоупотреби. Рискът може да бъде редуциран чрез подобрени механизми за физически и логически контрол на достъпа и постоянна бдителност.

Професионалистите по здравен мениджмънт трябва да дефинират високорисковите групи пациенти и да бъдат в състояние да преценят дали електронните системи притежават характеристики и функционалност, които могат да повишат риска от неправомерно използване или разкриване на данните за пациентите. На тази основа те могат да предлагат допълнителни мерки за защита за чувствителната информация при прякото сътрудничество със специалистите по информационни технологии (ИТ специалисти).

Гарантирането на сигурността на защитената медицинска информация на пациентите в ИТ системите изисква да се прилагат мерки за противодействие срещу неоторизирано използване и разкриване на тази информация. Например, в цитирания по-горе НIPАА стандарт за защита на информацията в сферата на здравето са дефинирани правила за сигурност (Security Rules [10]), които се прилагат към електронната форма на данните. Както правилата за конфиденциалност (Privacy Rules [11]), така и правилата за сигурност изискват да бъдат обхванати субектите в здравната сфера, които имат договорни отношения или съглашения с бизнес партньори, за да се гарантира, че последните ще защитават по подходящ начин електронните ресурси.

С оглед на разгледаните по-горе рискове за дефинираните категории „чувствителна“ информация се формира жизненият цикъл на проекта за информационна сигурност в здравеопазването. Авторьт предлага концепция за жизнения цикъл в следните етапи:

1. Идентифициране на информационните ресурси ${ }^{3}$;

2. Категоризиране на информационните ресурси;

\footnotetext{
Под „информационни ресурси“ в доклада се разбира информация, данни, носители на информация, информационни системи и техните компоненти.
} 
3. Оценяване на риска за информацията;

4. Съставяне на програма за управление на риска;

5. Проектиране и придобиване на специализирани информационни системи и услуги;

6. Създаване и прилагане на политики и процедури за сигурност;

7. Развитие и изпълнение на политика за санкциите.

Оценяването на риска от разкриване на информация е важна стьпка в цялостния план за поддържане на сигурността на системата, особено във връзка с безопасността на пациентите със специфични заболявания, които ги поставят в неравностойно и уязвимо положение в обществото.

Етапите 5 и 6 се развиват паралелно, тъй като системата за сигурност е вградена като функционалност в информационната система. Етап 5 от предложения жизнен цикъл сам по себе си притежава собствен жизнен цикъл, отразен в стандартите за разработване и придобиване на информационни системи, който не е обект на настоящото разглеждане.

\section{Решения}

В изпълнение на проекта за създаване на електронно здравеопазване се създава интегрирана информационна система (ИС). Информационната среда включва множество функционалности, базирани на съвременни технологии, с цел да се обхванат всички компоненти на здравната система. Централният елемент на ИС е базата от данни, която се използва от различните бизнес процеси и респективно от различните потребители (длъжностни лица), съобразно с техните роли в информационните процеси. Спецификата на данните и информацията обуславят изграждането на ядро за сигурност, съобразно с посочения в т. 2 жизнен цикъл.

За да се изпълнят изискванията за сигурност, е необходимо да се изградят политиките и процедурите за защита на информацията и да се извършва периодично обучение на персонала за стриктното им изпълнение.

Преди да се направи обобщение на мерките и средствата за сигурност, в този материал се разглеждат особеностите на информационните процеси в здравеопазването, които обуславят тези мерки.

Могат да възникнат особени обстоятелства, при които се изисква анонимност или специални мерки при идентификация на пациента или достьп до личното му досие: например, при случаи, които се отнасят до ВИП личности или лишени от свобода лица, също така за осигуряване на неприкосновеност на личния живот на работното място, при домашно насилие, насилие над деца или злоупотреби с уязвими възрастни, процесуално представителство, или при процедури за донорство на органи. В такива случаи е необходимо да се прилага механизъм за деидентификация, ограничаване на достъпа или генериране на псевдоним, за да се реализира по-висока степен на защита на конкретна информация за определен период от време.

За защита на информацията за изследванията и лечението на пациенти с ХИВ/СПИН се прилага използването на флагове или предупредителни съобщения. Електронната система трябва да съдържа функционалност, улесняваща изключването или разделянето на резултатите, които следва да бъдат защитени, когато не е налице необходимото съгласие на пациента. Същото се отнася и за размножаване на записите.

Със специално внимание се подхожда към досиетата на лица, свързани със злоупотреба с химически вещества и съответните зависимости. Системата трябва да осигурява механизми за създаване на допълнителен „слой“ на защита на тази информация. За оповестяване на тези записи се изисква специално разрешение, посочващо ясното съгласие на пациента или писмена декларация за забрана на разкриването от получателя. Пациентите имат право да отменят разрешението за разкриване на информацията писмено или устно и институциите трябва да прилагат механизми за проследяване и да спазват това изискване.

Електронните системи трябва да включват функции на ядрото на сигурността, базирани на ролеви достьп, пароли и одитни пътеки. Препоръчително е също така присвояването на псевдоними и номера на алтернативни сметки на пациенти, подложени на специални процедури или тестове. Системата трябва да бъде в състояние да свърже псевдонима или алтернативната идентификация с реалното юридическо лице и номера на сметка на пациента по сигурен начин, за да се гарантира защитата на медицинското досие на пациента и да се даде възможност за точно фактуриране, като същевременно не се нарушава неприкосновеността на личния живот на пациента.

Организациите трябва да бъдат активни при избора на софтуерни продукти, които предлагат функции за сигурност, в съответствие с техните нужди. Подходящата софтуерна система включва функционални възможности за ограничаване на достъпа, като се осигурява достьп само за служителите, работещи директно с пациента или тези с административни отговорности (например отдел по управление на риска, правен отдел). Контролните механизми следва да включват възможността да се редактира чувствителна информация, която не трябва да бъде оповестена.

Дейността на потребителите се обвързва с уникална идентификация, надеждно поддържане на одитни пътеки и детайлизирана документация. Одитните пътеки са от съществено значение за проследяване на потребителските дейности като четене на документ, отпечатване, редактиране, съхраняване и възстановяване на документи, и последващи заявки. Всички операции, извършвани с документите трябва да бъдат отразени с дата и час на създаване и съхранение или публикуване и да се прилага заверяване и подписване по електронен път или по друг надежден начин.

В системата се въвежда информация за права̀та за сканиране, публикуване и възпроизвеждане на документ, както и за пълномощно или друг правен документ, определящ права̀та на пациента или упълномощен представител. Организациите също изискват функционалност, чрез която потребителят се задължава да въведе обосновка за всеки подпис, с цел предотвратяване на неоторизиран ситопечат и неоторизирано сваляне на преносими устройства за съхранение.

В случая на контролирано събитие, например инцидент, разследване или съдебно производство трябва да има възможност досието да се превърне в „единица с ограничен достьп“, незабавно да се заключва и да се ограничава достьпа на персонала. Подобна функционалност предпазва досието да бъде разглеждано от членове на персонала, любопитни за подробности за инцидента. Записьт може да се „отвори” към конкретен служител за кратък период от време, когато трябва да бъде вписана допълнителна документация, но достъпът трябва да остане ограничен.

Функциите за сигурност предоставят на професионалистите възможност за проследяване на проблеми със сигурността, като например неподходящ достъп или подпис. Флагове и сигнали могат да послужат за съставяне на карта къде другаде се намират конкретни данни или кои служители са имали достьп.

Някои от мерките, които се препоръчват по отношение функциите за сигурност на системата са:

- идентифициране на лицето, което има пълномощия за достъп до досиета;

- въвеждане на сигнали или флагове за идентифициране на пациентите във всяка категория;

- прилагане на блокировки на достъпа до файлове с код за ВИП достьп; 
- изискване за електронен подпис при достъп до специфична информация, както и за специалните разрешения и забрани;

- включване на функции като присвояване на уникален идентификатор и парола за вход в момента на всяко подписване на документ. Подписьт следва да включва името на подписващия, датата, времето на изпълнение и смисъла на подписа (например, одобрение или авторство).

С въвеждането на нови електронни услуги е необходимо да се идентифицират новите рискове и да се актуализират политиките за сигурност. Те се привеждат в действие чрез прилагането на средства за защита, чрез които да се отговори на изискванията за минимален остатъчен риск относно сигурността на електронните информационни ресурси. Оценява се ефективността на въведените защитни механизми и процедури.

Мерките за сигурност могат да бъдат обобщени в следните категории: административни, физически и технологични (технически). ности:

Административните мерки включват следните дей-

- периодично преразглеждане на политиката за сигурност, която се прилага по отношение на медицинската информация, с цел актуализиране във връзка с нови рискове. Новите политики се основават на приложение на съвременни технологии за защита на информацията, например криптиране на данните;

- определяне на персонална политика за сигурност - кои лица имат право на достьп до информацията и права̀ за модифициране, кога и как се предоставя информацията на пациентите или на други сродни организации;

- въвеждане на новите политики в практиката, с което се намалява вероятността за успешни атаки към системите с цел компрометиране на информацията или използването ѝ по неоторизиран начин;

- извършване на одит и тестване на ефективността на мерките за сигурност;

- обучение на персонала за задължителното прилагане на мерките за сигурност и предвидените санкции при нарушения.

Физическите мерки се заключават в прилагане на нови контролни механизми на съоръженията и помещенията, в които са инсталирани системите (сьрвьрите и работните станции). Такива мерки са:

- механизъм за контрол на достъпа до съоръженията - ограничения за физически достъп до съоръженията, където се помещава системата, като същевременно се гарантира упълномощено право на достьп на персонала;

- регулиране на режима за използване на работните станции - спецификации за правилна употреба на работните станции, които имат достъп до електронните здравни досиета;

- сигурност на работните станции - определяне на ограничения за достъп до работни станции; създаване на система от роли и правила за достъп до защитената информация;

- поддържане на характеристиките на физическата среда - електрическа мрежа, климатизатори, отоплителни системи и устройства за пожарна безопасност;

- контрол на устройствата и носителите - предписания за използване и унищожаване на хардуер и електронни медии, които съдържат защитена информация във и извън организацията; управление на тези компоненти в рамките на един жизнен цикъл, включително унищожаване, повторна употреба на носителите, отчетност и архивиране на данни и съхранение.

Техническите и технологичните мерки включват ме- тоди и средства за обработка на информацията при съхранение и предаване в мрежовата среда, както и за контрол на достьпа. Прилагат се решения за ограничаване на достьпа до електронната информация и противодействие на неоторизирания достъп. Необходима стьпка е сертифицирането на електронните здравни досиета, както това е направено посредством ONC Standards and Certification Criteria [12]. Основните мерки за сигурност включват:

- контрол на достъпа - разрешаване на достъп до ЕЗИ само на лица или софтуерни програми, които имат съответните права̀ за достъп до данни, посредством уникални протоколи за идентификация на потребителя;

- регламентиране на процедури за достъп в извънредни ситуации на няколко нива̀;

- автоматично прекъсване на сесия след предварително определено време на бездействие;

- прилагане на процедури за криптиране и декриптиране на данните;

- одитни проверки - одит на операциите: записване и анализ на функциите, които съдържат или използват защитена информация, осъществени в системата. Поддържане на журнали с подробна история на достьпа до данните;

> осигуряване на цялостност - защита на ЕЗИ от неоторизирана промяна или унищожаване, включително прилагането на механизми за удостоверяване;

- удостоверяване на лице или същност - проверка на физическото или юридическото лице, което иска достъп до ЕЗИ и потвьрждаване чрез доказателство за самоличност. Предвижда се изискването на цифров подпис;

- сигурност на предаване - предпазване от неоторизиран достьп до ЕЗИ, който се предава по електронна съобщителна мрежа.

Задължителните технологични средства, които се прилагат са: антивирусни програми и защитни стени в мрежата; използване на виртуални частни мрежи; сертифициране на приложенията и технологиите, които се използват при съхраняване и обмен на информацията; архивиране на данните - съхраняване на информацията на втори файлов сървьр, който може да бъде пространствено отдалечен и т.н.

Примерна схема на избор на технически мерки, с оглед на очаквания риск е представена в Таблица 1

\section{Аискусия}

ИТ специалистите, натоварени със защитата на данните, трябва да гарантират, че дадена система включва функционалност, която ще даде възможност на организацията да изпълни своите регулаторни и оперативни изисквания.

Когато става въпрос за защита на информация с висок риск, специалистите трябва да определят местоположението на тази информация в системите на организацията и да прилагат специфичните изисквания, свързани с категориите информация, указани в нормативните актове. Наложително е да се идентифицират функциите в електронните системи, които създават риск и да се поставят ограничения за достъпа и използването на чувствителната информация. Друг съществен аспект е идентифицирането на мерките за сигурност, които предлагат по-високи степени на защита и планирането на тяхното използване. От голямо значение е производителите на специализиран софтуер да прилагат решения за сигурност при разработването, за да отговорят на изискванията на потребителите за защита на чувствителна информация.

При избора на електронна система, организацията потребител трябва да разчита на независима оценка на системата, а не само на предоставената от продавача документация за функционалност. Организацията определя дали да приложи допълнителни мерки за сигурност, за да не рискува 
Таблица 1.

\begin{tabular}{|c|c|}
\hline Рuск & Технически средства \\
\hline $\begin{array}{l}\text { Информацията е уязвима към } \\
\text { неразрешено разкриване, на- } \\
\text { пример, когато е оставена } \\
\text { ясно видима на екрана на } \\
\text { компютъра след употреба. }\end{array}$ & $\begin{array}{l}\text { Компютърният акаунт и екранът се } \\
\text { скриват след определен период на } \\
\text { неактивност и само упълномощени } \\
\text { потребители могат да влизат по- } \\
\text { вторно в системата. }\end{array}$ \\
\hline $\begin{array}{l}\text { ЕЗИ се обменя с външни до- } \\
\text { ставчици, свързани с орга- } \\
\text { ните на общественото } \\
\text { здравеопазване или е преза- } \\
\text { писана върху външна медия, } \\
\text { преносими устройства или } \\
\text { личен лаптоп. }\end{array}$ & $\begin{array}{l}\text { Всички данни се криптират и пре- } \\
\text { насят през защитени комуника- } \\
\text { ционни линии за данни. } \\
\text { Прилагане на ограничения за дви- } \\
\text { жението на ХИВ/СПИН свързани } \\
\text { данни в преносими устройства за } \\
\text { съхранение. }\end{array}$ \\
\hline $\begin{array}{l}\text { Здравни работници, различни } \\
\text { от тези, които са упълномо- } \\
\text { щени да работят с данните } \\
\text { на пациента използват си- } \\
\text { стемата, за да направят } \\
\text { преглед на данни за статус } \\
\text { на ХИВ/СПИН пациент. }\end{array}$ & $\begin{array}{l}\text { Изискване на парола за достъп до } \\
\text { мецинското досие. Дефиниране на } \\
\text { роли и прилагане на ролево-бази- } \\
\text { ран достъп на потребителите. Про- } \\
\text { вежда се рутинен одит, за да се } \\
\text { установи кой има достъп до чув- } \\
\text { ствителните данни. Всички служи- } \\
\text { тели се обучават за правилници, } \\
\text { наредби и последствията от неото- } \\
\text { ризиран достъп. }\end{array}$ \\
\hline $\begin{array}{l}\text { Здравни работници, упълно- } \\
\text { мощени да имат достъп до } \\
\text { ЕЗИ на пациента, но нямат } \\
\text { разрешение да знаят състоя- } \\
\text { нието на ХИВ/СПИН паци- } \\
\text { енти по невнимание попадат } \\
\text { на статус на ХИВ/СПИН паци- } \\
\text { ент. }\end{array}$ & $\begin{array}{l}\text { Информацията, свързана със ста- } \\
\text { туса на ХИВ/СПИН пациенти (резул- } \\
\text { тати от изследвания, лечение, } \\
\text { както и участие в клинични изпит- } \\
\text { вания или изследвания) се изолира } \\
\text { в определен сегмент на базата от } \\
\text { данни, който не може да бъде до- } \\
\text { стъпен неволно или умишлено без } \\
\text { разрешение. Конфигуриране на ро- } \\
\text { лево-базиран достъп в системата. }\end{array}$ \\
\hline $\begin{array}{l}\text { Паролите са оставени от- } \\
\text { крити или са уязвими към } \\
\text { кражби от външни лица, } \\
\text { кочто искат да придобият } \\
\text { пациентски данни незаконно. }\end{array}$ & $\begin{array}{l}\text { Въвеждане на система за иденти- } \\
\text { фикация на потребителя. Използват } \\
\text { се допълнителни кодове за защита } \\
\text { при влизане в системата - изискват } \\
\text { се отговори на няколко въпроса, } \\
\text { или пръстови отпечатъци или се } \\
\text { прилага ирис- сканираща техноло- } \\
\text { гия. Приемане на ясна политика за } \\
\text { пароли и обучение на персонала } \\
\text { относно политиката. }\end{array}$ \\
\hline
\end{tabular}

сигурността или достъпа до данните. Оценката се извършва от гледна точка на функционалност и сигурност, за да се изпълнят оперативните изисквания и да се гарантира неприкосновеността на информацията.

Специалистите по здравен мениджмънт следва да си сътрудничат с ИТ колегите си и да изградят отношения на доверие и работа в екип, тъй като експертите от двете области на компетентност трябва да обединят усилията си към постигане на общата цел за подобряване на грижите за пациентите чрез информационната технология.

Работата с високо чувствителна информация в информационните системи в здравната сфера изисква специализирани функции на системата. Липсата на тези функции може да ограничи използването на системата до определени категории данни с висок риск.

Способностите на системата, които позволяват реализиране на съответните степени на защита включват:

- дефиниране и въвеждане на роли на служителите и определяне на специализирани работни места, чрез което се ограничава достъпа до предварително определени категории информация за пациенти, срещи и документи;

- въвеждане на показатели на ВИП статуса, които ограничават достъпа до информацията на специфични пациенти, като достьп се разрешава само с изричното сьгласие на пациента;
- задаване на псевдоним на пациент с цел да се прикрие неговата самоличност за определен период от време;

> ограничаване на достьпа до информацията на пациентите за специалисти, които не са опълномощени (например, при консултация);

блокиране на достьпа до конкретен документ или лабораторен резултат, или маскиране на определени записи.

Информацията, достъпна за страни извън организацията, също може да бъде изложена на риск. За неидентифициран потребител е лесно да установи достьп до мрежата, ако отдалечената връзка не е защитена. Прилагат се допълнителни защити, свързани с предаването на информация в мрежата и работата с носителите на информация. По този начин се гарантира сигурността при достъп до информацията от места извън контрола на организацията собственик.

Мобилните устройства и носителите, съдържащи чувствителна информация, които се изнасят извън организацията трябва да бъдат защитени в случай на загуба или кражба. Информацията трябва да бъде криптирана и да се прилагат мерки за сигурност на достьпа.

Риск съществува и при изпращане на факс, съобщения и електронна поща на защитена здравна информация. Прилага се криптиране на информацията при предаване и одит на сесиите. Възможно е да се изисква сесиите да бъдат блокирани при съмнения за неоторизиран достьп.

От значение е и процесът на поддръжка на системата от ИТ персонала. Необходимо е да се определи нивото на достъп на техническия персонал и одиторите. Ако поддръжката на системата изисква достьп до базата от данни на приложението, в което се съхраняват данните за пациента, следва да се определят ролите и отговорностите на персонала. Важен въпрос, който трябва да се реши с процедурите за сигурност е как ще се извьршва профилактиката на системата и блокирането на достьпа на техническия персонал до данните на пациентите. Също така е необходимо да се решат и някои практически въпроси, свързани с възможността за дистанционна поддръжка и опълномощаване на външна фирма за тази дейност. Този процес изисква създаване на съответни одитни пътеки и очевидно усложнява контрола на сигурността.

Една специфична хипотеза е свързана с възможността оторизиран потребител да промени ограниченията за достъп при извънредни ситуации. Необходимо е да се регламентира кой има право на това, как се контролира този процес и подлежи ли той на одит.

Особено място в политиката за сигурност заема подготовката на персонала за работа със системата, придобиването на знания за рисковете за сигурността и убеждение за необходимостта от стриктно спазване на мерките за защита. Системните функции сами по себе си не гарантират неприкосновеността на личната информация и сигурността. От съществено значение е позицията на ръководните органи по отношение на информационната сигурност. Здравното ведомство и подчинените му организации трябва да развият политики и процедури, насочени към човешкия фактор и да извършват обучение и култивиране на разбиране относно сигурността на чувствителната информация.

\section{Заключение}

Информационната среда в здравеопазването съдържа висок риск по отношение на основните характеристики на информацията - тайна, цялостност и наличност. Някои от основните проблеми са предизвикани поради следните причини:

- софтуерните програми са разработени от различни компании, на базата на различни технологични решения;

- не се прилага единна политика, относно разработ- 
ването на здравен софтуер и той не се сертифицира, с оглед на необходимостта от високо ниво на сигурност на информацията;

- отделните приложения са интернет-базирани и функционират в среда, уязвима към външни и вътрешни атаки;

- не са дефинирани изисквания по отношение на мрежовата сигурност (за Република България - освен тези в Наредбата за задължителните общи условия за сигурност на АИС или мрежи, в които се създава, обработва, съхранява и пренася класифицирана информация [13]);

- не са разработени регламентиращи актове по отношение на защитата на чувствителната информация и данни за пациентите (електронните медицински досиета) (частично тези въпроси са засегнати в Закона за защита на личните данни).

Поради тези причини е необходимо да се работи активно в посочените направления, за да се намери последователно и планомерно решение на дефинираните проблеми и недостатъци. Насоките за развитие са свързани с изясняване на специфичните изисквания към сигурността на информацията в здравната сфера, с цел гарантиране на безопасността на гражданите като пациенти и отразяването им в националното законодателство.

\section{Библиография}

1. Ensuring Security of High-Risk Information in EHRs, http://library. ahima.org/xpedio/groups/public/documents/ahima/

2. ISO 21549 - Health Informatics Package, 2007-2014, ISO 21549-5:2008, Health informatics - Patient healthcard data - Part 5: Identification data.

3. Персонализирана ИС в НЗОК съчетава съвременна ИТ архитектура и сигурност на информацията, Cio.bg, бр. 1/2014.

$\begin{array}{ll}\text { 4. https://pis.nhif.bg/main } & \text { 5. http://mariaradeva.com }\end{array}$

6. Закон за защита на личните данни, 2002, посл.изм. и доп. 2013

7. European charter of patients' rights, 2002

8. http://www.hhs.gov/ocr/privacy/hipaa/administrative/statute/hipaastatutepdf.pdf

9. Reassessing Your Security Practices in a Health IT Environment, http://www.healthit.gov/providers-professionals/implementationresources/reassessing-your-security-practices-health-it.

10. HIPAA Security Rule, http://www.hrsa.gov/healthit/toolbox/healthitimplementation/index.html.

11. HIPAA Privacy Rules, http://www.hhs.gov/ocr/privacy/hipaa/understanding/summary/index.html

12. ONC Standards and Certification Criteria, http://www.healthit.gov/policyresearchers-implementers/standards-certifications-criteria-final-rule, 2012

13. Наредбата за задължителните общи условия за сигурност на АИС или мрежи, в които се създава, обработва, съхранява и пренася класифицирана информация, 2003, посл. изм. 2014, www.dksi.bg.

\section{Автор}

Доц. Юлияна Каракънева - Нов български университет

ИСТОРИЯ НА МЕАИЦИНАТА

\section{ЛЕКАРИТЕ ОТ РОДА ЧАЛЬКОВИ - ВЪЗПИТАНИЦИ НА ВОЕННО-МЕДИЦИНСКОТО УЧИЛИЩЕ В ЦАРИГРАД}

$\mathrm{H}_{3}$ М. Петкова

ящата статия има за цел да представи основни факти от биографиите и обществената и медицинската дейност на лекарите от големия възрожденски род на Чалъков(ц)и от Копривщица - възпитаници на султанското Военно-медицинско училище в Цариград. Тъй като признаците на проучването са дескриптивни, е приложен историко-документалният подход.

Много научни проучвания и публикации отразяват състоянието на образованието и културата - в частност на медицинското образование, медицината и здравеопазването - на поробените балкански народи през XV-XIX в. Особено високо фактологична е книгата на акад. Ив. Снегаров за турското владичество като пречка за културното развитие на българския и другите балкански народи, което се дължи, според цитирания от него английския пътешественик R. Walsch (1827) на решителната враждебност на туризите към знанията.

Що се отнася конкретно за медицината, акад. Снегаров пише: „Кьм средата на XVI в. в Цариград нямало никакви аптеки, само дрогерии. Гръики лечители-практици сновели из българските земи чак до втората половина на ХІХ в. също персийци, турции и евреи."

Навлизащият в Турската империя капитализъм с неговите нови форми на икономика и отношения обаче възражда за живот и у българите забранени от 5 века културни, просветни и духовни дейности. Възражда се подтисканата потребност към просвещение и наука, особено към естествените и медицинските науки. Първото поколение български лекари учат в прочути европейски медицински университети във време на бързо и интензивно развитие на естествените и медицинските науки, на химията и физиката. Те са следовници предимно на доминиращите тогава идеи на френските просветители и енциклопедисти, а лекарите възрожденци са съпричастни предимно към книжовно-просветното дело и борбата за църковна независимост.

Макар и по-бавно турската държава приема нормативни документи, които регламентират дейността на медицинската практика и откриването на общински аптеки. При султан Махмуд II се открива Имперското медицинско училище (1827) - център на френската медицинска школа. По идея на Садих Ефенди се открива и гражданско медицинско училище (1868). Приема се Правилник за централизирано медицинско управление (1871). По цялата територия на империята се разгръща мрежа от военни болници по английски и немски образец.

Голяма глътка въздух за българите е откриването на медицински училища в Атина (1829), Цариград (1827) и Букурещ (1842). Тъй като тогава турската държава не признава българите за отделен народ, през първите 26 г. Военно-медицинското училище в Цариград не приема български младежи, с изключение на тези, които могат да плащат таксите.

Общо за периода 1827-1877 г. във Военно-медицинското училище в Цариград постъпват 139 българи и се дипломират 71. Завършилите получават чин майор, стажуват и ги разпределят по турските военни гарнизони. Тези, които са учили на държавна стипендия, са задължени да работят като военни лекари в турската армия до пенсионирането им. 